\title{
Entrepreneurial learning: a narrative-based conceptual model
}

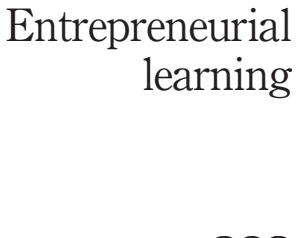

David Rae

\begin{abstract}
Purpose - Entrepreneurial learning is an important area of enquiry which is not well understood in either the academic study of entrepreneurship or the practical development of new entrepreneurs. The article aims to explore two questions: first, how do people learn to work in entrepreneurial ways - are there significant processes and experiences in their learning, which can be related to existing learning theories? Second, can a useful framework to understand entrepreneurial learning be developed and applied both in entrepreneurial practice and conceptually by educators?

Design/methodology/approach - The article includes a brief critical review of the theoretical literature in the areas of entrepreneurship and learning. Thematic discourse analysis is used to interpret the life story narratives of three entrepreneurs in the creative industries. Material from their learning experiences is used to support the development of a conceptual model. This demonstrates connections between the emergence of entrepreneurial identity, learning as a social process, opportunity recognition, and venture formation as a negotiated activity.

Findings - The principal finding is to propose a conceptual framework of entrepreneurial learning as a triadic model, including major themes of personal and social emergence, contextual learning, the negotiated enterprise, and a group of 11 related sub-themes.

Practical implications - Applications of the model in entrepreneurship education, work-based learning and practice, are proposed, within and beyond the context of the creative media industry.

Originality/value - The paper develops an original and distinctive conceptual understanding of entrepreneurial learning through analysis of entrepreneurs' experiences, based on a social learning and constructionist perspective.
\end{abstract}

Keywords Entrepreneurialism, Learning, Narratives

Paper type Conceptual paper

\section{Introduction and rationale}

Entrepreneurial learning has emerged as an important area of enquiry in relation to both the academic study of entrepreneurship and the practical development of new entrepreneurs, yet it is an area which is not well understood (Deakins, 2000), This article draws on a study of entrepreneurial learning in the creative and media industry (Rae, 2003), which explored these two questions:

(1) How do people learn to work in entrepreneurial ways: are there significant processes and experiences in their learning, which can be related to existing learning theories?

(2) Can a useful framework for the understanding of entrepreneurial learning be developed and applied, both in entrepreneurial practice and conceptually by educators? 
JSBED

12,3

324
The article offers two propositions. The first is that learning is a fundamental and integral part of the entrepreneurial process, in which the human, social and behavioural activities are of as much concern as the economic aspects which are often highlighted. The second proposition is a conceptual model which explains the entrepreneurial learning process and can be applied in entrepreneurial education and development.

Entrepreneurship is an inter-related process of creating, recognising and acting on opportunities, combining innovating, decision making and enaction; this is consistent with definitions by (for example) Shane and Venkataraman (2000), Learning is an emergent, sense-making process in which people develop the ability to act differently, comprising knowing, doing, and understanding why (Mumford, 1995), Through learning, people construct meaning through contextual experience and create new reality (Weick, 1995), Both entrepreneurship and learning are inherently constructivist, behavioural and social processes. The term entrepreneurial learning therefore means learning to recognise and act on opportunities, and interacting socially to initiate, organise and manage ventures.

\section{Summary of relevant literature}

Addressing the first question, of how people learn to work in entrepreneurial ways, the dominance of economics-based and entitative thinking is long-standing, although it offers a limited understanding of the human and social processes of entrepreneurship and learning (Davidsson et al., 2001), That is not to disregard the contribution of economics, for although Schumpeter (1934) and Kirzner (1973) observed the importance of learning in the entrepreneurial process, Binks and Vale (1990) commented on the limitations of economic theory in understanding the human, sociological and psychological aspects of entrepreneurial behaviour. Recent studies of entrepreneurial cognition, such as Mitchell et al. (2002) and Parker (2004) have been limited by the cognitivist paradigm of individual (not social) and cerebral (not behavioural) conceptualisation. The results can be seen in the algorithmic "dynamic model of entrepreneurial learning” produced by Minniti and Bygrave (2001), As Spinosa et al. (1997) observed, there is a need to move beyond such entitative and positivist approaches to entrepreneurship in order to create understanding of the human processes involved.

The main conclusion which can be drawn from the extensive writing on entrepreneurship education is that while education can provide cultural awareness, knowledge and skills for entrepreneurship, the "art" of entrepreneurial practice is learned experientially in business rather than the educational environment (Gibb, 1993, 1996; Gorman et al., 1997; Jack and Anderson, 1999), Learning must be explored as a contextual and active rather than a purely educational process, which raises the second question, of whether a framework can be created to understand entrepreneurial learning.

The cognitive paradigm has also dominated the study of learning, and is limited by using the concept of individual information processing to understand the human mind and the ability to learn (Gagné, 1977; Bandura, 1986), Beyond cognitivism, Mead (1934), Kolb (1984) and Mumford (1995) developed experiential and social theories of learning which combine action, conceptualisation and social practice, while the contributions of language, constructivism and discourse in understanding learning have developed through the work of Kelly (1955), Vygotsky (1962) and Harré (1989), Wenger (1998) developed a comprehensive social and behavioral theory of learning, including dimensions of meaning, practice, identity and community. This provides a conceptual foundation for a model of entrepreneurial learning which accommodates social 
participation and human action as well as cognition, enabling advanced learning theory to be applied to entrepreneurship. It also enables progression from individual conceptions of entrepreneurial learning (Deakins and Freel, 1998; Cope and Watts, 2000; Rae and Carswell, 2001).

Three concluding questions can be drawn from the literature on entrepreneurial learning. First, how and why do people develop entrepreneurial identities? Second, how do people learn to recognise and work on opportunities which arise from their social experiences? Finally, how do people learn to create and manage enterprises through interpersonal processes? By exploring these three questions, there is the potential to create new understanding of entrepreneurial learning. The methodology for this is proposed in the next section.

\section{Methodology}

The methodology used in this study is social constructionist (Gergen, 1999), narrative (Polkinghorne, 1988) and interpretive (Schwandt, 1998), Narrative approaches have become recognised as valid methods in the interpretive study of entrepreneurship (Hjorth and Steyaert, 2004), In this case narrative is used to explore the entrepreneurial learning process in the "lifeworld" of the entrepreneur, gaining access to their accounts of their actions and interactions with others within their environment, their personal and business venturing, and their learning.

The research was undertaken in the creative media industry in the United Kingdom which features conditions of rapid change, significant risk and volatility, with opportunities for new venture creation and growth being highly apparent (Leadbeater and Oakley, 1999), However the entrepreneurial process and its learning dimension is not well understood, with a "missing middle" in public policy in relation to the learning and development needs of creative entrepreneurs (Raffo et al., 2000), Therefore new understanding of academic and practical value could be created, and whilst this would be limited contextually it might be extended and applied in cultural entrepreneurship beyond the UK and possibly in other sectors.

The study identified emerging entrepreneurs and followed their personal and business development through a series of in-depth life story interviews. The methodological challenges which arose from this approach included the relational issues of selecting and maintaining the participants' engagement in documenting their story; reflexivity, in making sense of the researcher's own interaction with the research participants, material and process; and interpretive, in creating meaning of wider relevance from the study.

The study was limited to three participants to enable depth rather than breadth of coverage. They were identified through recommendation, networking and social contact, then invited to participate. The criteria for selecting these participants required them to be currently running a cultural media business, differing in type from the others selected; prepared to participate fully in the research; and intending to actively grow and develop their business in innovative ways. The participating entrepreneurs and their businesses, which were presented as case studies, included:

- Sawari Culture, a mail-order business supplying entertainment and media products to the growing Asian market (Kal).

- Blue Fish, a corporate design, identity and marketing agency (Tony).

- Shires FM, an independent radio station group (Mike). 
JSBED

12,3

326

The researcher acted as co-author with each participant over a two-year period in which multiple life-story interviews took place to create an account of their experiences in business and personal development. The scope of the interviews included the story of their career and business to date and exploration of key learning episodes such as their reasons for deciding to start a business and subsequent experiences, changes and learning points. Each interview was transcribed and coded against a set of 27 categories generated through discourse analysis (Potter and Wetherall, 1987), This allowed cross-case comparison of similarly coded speech extracts and theory building. Related material gathered for supplementary and corroborative detail included social observation of the participant in business meetings and other interactions, conversations with their colleagues, and sampling the creative and commercial output of their enterprise. The material was edited into a draft case study and the narratives were reviewed with the participants and compared, using the coding structure, to develop the conceptual model of entrepreneurial learning.

\section{Findings}

Three major common themes were identified from the accounts, which related to the participants' learning and also connected with the conclusions from the literature review. These themes consist of personal and social emergence; the negotiated enterprise; and contextual learning. Within these major themes, a total of 11 subsidiary themes were identified. Together these constitute the triadic model of entrepreneurial learning which is shown in Figure 1 and is followed by a description of the major and subsidiary themes, illustrated by extracts from the case material.

\section{Personal and social emergence}

Personal and social emergence is the development of entrepreneurial identity, including early life and family experiences, education and career formation, and social relationships. It includes the formation of a sense of self and of future aspirations. In

Figure 1.

Triadic model of entrepreneurial learning

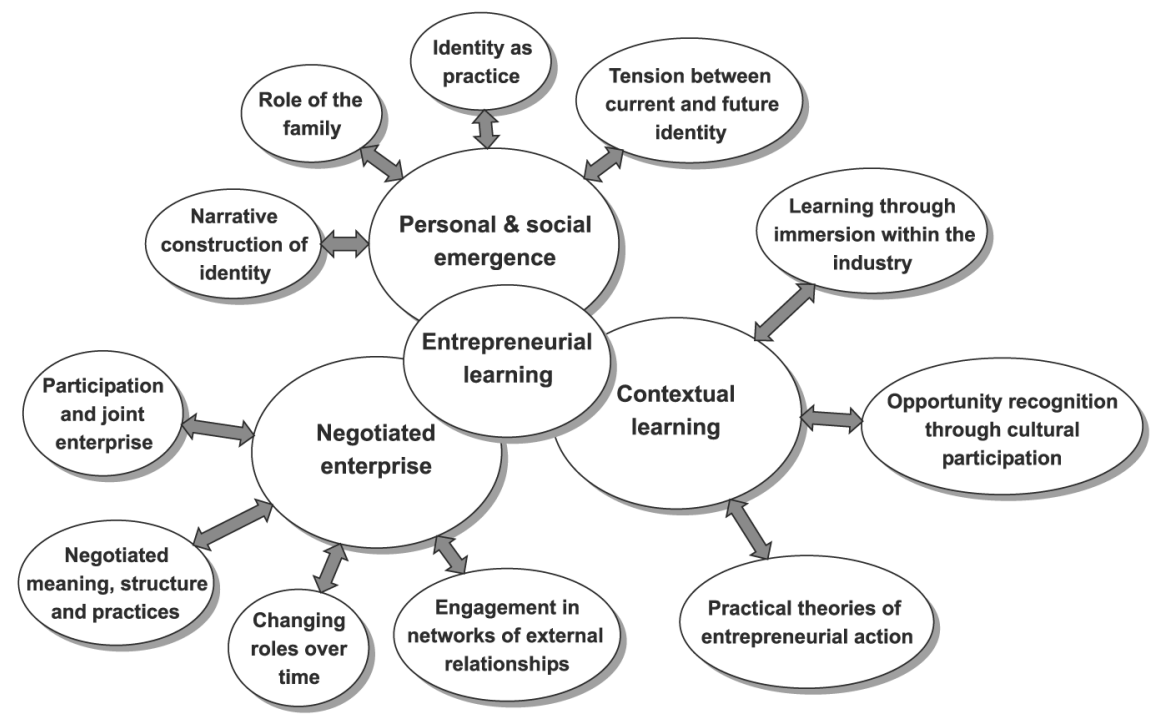


becoming recognised as an enterprising person, people seek to renegotiate their personal and social identities which express who they are, who they want to be, and how they prefer to be recognised within their social context. The process of personal and social emergence is illustrated by this extract from Kal's story in the Sawari Culture case:

I was working in my husband's print business, and I realised I wanted to do something more than just the accounts. The industry was male dominated, most of our clients were Asian men who thought that "she's just the wife, she does the book-keeping, that's all". At the time I didn't challenge it, I thought this is the way it's supposed to be. I'm not like that any more, I do challenge it.

It was a major thing for my husband to understand that I wanted to do creative things because we'd come from a very orthodox upbringing with set views about what girls and boys did. I started to do computer design work which I really enjoy. But there came a stage when I didn't want to be seen as just a wife and a mother. I wanted recognition as a person in my own right. Something inside me said, “This isn't right, I can do a lot more than this".

That made me realise that I wanted my own business, you have an idea for something you want to do and you develop it. I want to achieve something for myself. It's not that I want to say "I've done all this myself, created a business of my own", I can't do that. You have to have support from people and that comes in a lot of forms. But I've always had this energy and belief that I want to achieve something.

Kal's story exemplifies the creation of entrepreneurial identity through personal and social emergence, in which the four sub-themes of narrative construction of identity, the role of the family, identity as practice, and tension between current and future identity can be recognised.

People construct their identity through narrating autobiographical stories in which they are the central actor, as well as narrator and author. Their entrepreneurial identity is socially negotiated as they makes sense of their own identity and renegotiate or "re-invent" themselves in their own and others' perceptions through the stories they tell. Change and development occurs as learning experiences shape their personal and social identity.

The role of families is significant in shaping identities and actions. Entrepreneurial stories are constructed with reference to personal relationships with parents, spouses, and children. In turn, the relationship with family members is changed through entrepreneurship. This is especially the case within the "family business" as we see in Kal's story, in which her identity is renegotiated within her family relationships, marriage and children. The male participants talked of their roles as fathers and husbands and of how they managed their business identities alongside the familial. It is apparent that the negotiation of roles and expectations, in which cultural and social traditions, such as gender roles of husband and wife, father and mother, play an important part in the construction of identity. This family dimension cannot be omitted from a consideration of entrepreneurial development, although the dynamic changes according to family circumstances (e.g. absent parents).

People develop identity as practice from the personal and social activities, practices and roles which they experience, often through early employment. As Kal discovered her talent for creative design from experience, people learn how to apply their abilities within networks of social and industry relationships. These abilities, skills and know-how are often applied in the core activity of the new enterprise. 
JSBED

12,3

328
In entrepreneurial stories, there is often tension between current and future identity, where dissatisfaction with existing reality is expressed through entrepreneurial action; this may be the point where they "become an entrepreneur". These can be powerful episodes in which there is an emotional recognition that the experienced reality did not "feel right", which is not only a cognitive dissonance but also conative and affective (Festinger, 1957), Such decisions to create new ventures are often connected with the rejection of an unsatisfactory present, the urge to create a new reality and changed identity. So people move from being dissatisfied employees, in work roles where practices and identities are defined socially by others and are at odds with what "feels right", to create new reality through their business ventures, enabling them to work in ways consistent with their personal values and practices.

In terms of identity, the entrepreneurial act is translating imagined possibilities of "what could be" into enacted reality, taking responsibility for shaping future events. It is moving from assuming an identity defined by others, such as work and family roles, into creating a new identity. It is to experience emotional uncertainties, drawing on resources of self belief which accompany this shift from being a participant to being the "auteur" of an entrepreneurial drama. This change requires the actor's personal confidence and self-belief that it "feels right" and they are able to make it happen.

\section{Contextual learning}

Contextual learning occurs through participation in community, industry and other networks in which individual experiences are related, compared and shared meaning is constructed. Through these situated experiences and relationships people can develop intuition and the ability to recognise opportunities. Such learning connects personal emergence with the negotiation of the enterprise, as people learn in their social context "who they can become" and "how to work with others to achieve their ends" as well as the realism of "what can and cannot be".

This theme is illustrated by an extract from the Shires FM case which demonstrates Mike's contextual learning and the three sub-themes of learning through immersion within the industry, opportunity recognition through cultural participation, and practical theories of entrepreneurial action:

I started working in radio when I was 15 . I did a few stints on hospital radio, then got into the local radio station for work experience, It seemed like a lot of fun, I wanted to be in there to do things I could show were worthwhile.

I did that at school, working evenings and weekends. I presented a programme of my own when I was 17 and kept it up at University, after that the same company offered me a management trainee job running a tiny new radio station.

I had to make things happen, it was sink or swim to make it work. Then I went to run a larger radio station with real power to manage people. I learned that whilst I may have goals, visions, targets, my job is to help other people achieve them because I can't do it on my own. For six months it went very well, revenue and audiences grew.

But then there was a market downturn, the company went in a different direction and I was getting increasingly fed up, I left, taking a huge risk, but the contradiction with what I believed was too much.

There was no commercial radio station here. So I put in an application for the licence when it was advertised. I found the shareholders and persuaded them that they wanted to invest. We were outsiders but we won the licence and that's how I got to be running Shire FM. 
I hadn't liked the experience of having to do things in a radically different way from what I believed was right, and I'd been successful, so it was an opportunity to run an organisation from scratch how I believed would work.

I can tell you what works for us because I've done it a number of times. It's part-art, part-science, part what-feels-right. How much notice did I take of research when I put together our radio schedule? Very little, I know what works. It's an approach, it's gut feel. We know our market place, we've worked out our own answers and we're going to stick to them.

Mike's story recalls career-long learning through immersion within the radio industry, progressing from "odd job person" to broadcaster, producer, station manager and ultimately to managing director. This supports the findings of Gibb Dyer (1994) and Mitton (1997) who noted the profound influence of career experience on entrepreneurial formation. This includes the development of skills, expertise and social contacts from employment. Such learning is relational, functional and problem-solving in nature, finding out by participation and social interaction how things are done, and establishing routines which work in given situations. It occurs, as Gibb (1996) relates, through discovery and experiential learning, providing the intuitive practices, skills and insights people use in creating their own businesses.

People can learn to recognise opportunities and future possibilities through participating in social and industry networks. Mike noticed the gap in local radio for Shires FM and acted on the opportunity to create a new venture within a context which he knew. Prospective sense making is necessary to envisage the future and imagine how the venture can be created, before all the necessary knowledge, circumstances or conditions exist. This is a process of creative, associative learning, of putting ideas, opportunities, technologies and resources together in new ways, and acting when the market and other extrinsic factors such as regulation and the absence of competition provide advantage.

Mike related "what works" for him; entrepreneurs, through their experience and contextual learning within the industry, develop such rules and practices. Such knowledge, gained from experience, intuition and sense making of "what works", why, how and with whom, constitute practical theories (Rae, 2004), These enable people to reduce risk through prior experience because they "know what they are doing".

\section{The negotiated enterprise}

The concept of the negotiated enterprise is that the business venture is not enacted by one person alone, but through negotiated relationships with others. The ideas and aspirations of individuals are realised through interactive processes of exchange with others within and around the enterprise, including customers, investors and co-actors such as partners or employees. This extract from the Blue Fish case study illustrates through Tony's story the four sub-themes of participation and joint enterprise; negotiated meaning, structures and practices; changing roles over time; and engagement in networks of external relationships.

Three of us established Blue Fish when the firm we worked for went into liquidation. We didn't try to keep the old clients and decided we'd do things really honestly, be straight with clients, not bullshit our way into jobs, build it up steadily, everything that went wrong before we'll do right. We rented a single room to work from and worked ludicrous hours to get off the ground - survival was the name of the game. We didn't believe we were working hard enough unless we were working past midnight.
Entrepreneurial learning

329 
JSBED

12,3

\section{0}

But with the long hours we became prisoners in our own company, and realised we wouldn't continue to enjoy it. We knew we had the seeds of something good but we had to work out what we had done wrong and what we were doing right. We were messing around, trying to find our feet, establish our credentials, starting to understand how we made a profit or a loss.

Our accountant made us each write down what we wanted for this business, when we wanted to sell it, and what tone of voice we wanted to present to the market. We wrote down four words between us: creative, effective, fun, and integrity. Those words summarised the business and became our values. We agreed we wanted to be out of the business before we're 50 with about $£ 2 \mathrm{~m}$ each, so we wrote a 20 -year plan to get the profitability levels and get ourselves out of the business, putting in a strong management structure that would run the business for us. Now we're bang on target, we work 40-50 hours per week but never more than that.

As a team we were great at generating ideas and getting people fired up but awful at following through to a successful conclusion. We suffered from failure to implement and collective irresponsibility where no-one was responsible for making decisions. Now we've established specific roles for each of us, we "work on the business not in it", and get things done much faster.

We now aim to employ only brilliant people, not only different to us but better than us. We try not to recruit people in our own likeness which is the classical mistake we made early on. We make sure people fit into a specific role and it seems to work.

The founders of Blue Fish are joint participants in the enterprise with their employees. As Wenger (1998) noted, "the enterprise is joint ... in that it is communally negotiated". A vital aspect of the entrepreneurial learning process is the ability to engage others constructively towards that end, and this is demonstrated in all three of the cases. It is necessary for the founders to create shared belief in the new reality of the venture, and for this to become a means of realising personal dreams and aspirations through participative action. This sublimates individual identity to the collective identity of the enterprise, aiming for mutually desired outcomes such as wealth creation, economic survival or the production of a particular activity. This shared interest is a necessary condition for joint enterprise, accompanied by a social learning process in which people learn to work together. Joint enterprise also involves combining resources such as expertise, finance and technology to enact the business idea.

As Tony related, the founders of Blue Fish agreed four words which became their values. Within the enterprise, a distinctive culture emerges, based on negotiated ways of working which reflect both the founders' style, language, ambitions and ways of working, and those of the employees. The founders hold formal power and ownership of the business, yet they must learn to recognise the participation of people within the business, whose concerns and aspirations influence its culture, structures and practices. Conflict and disagreement often occur as an integral aspect of this negotiation.

Just as individuals develop practical theories in the joint enterprise, these theories and practices become a shared repertoire of "what works"; as in a community of practice, what is learned does not belong to any single person, but rather is dispersed among the community (Wenger, 1998; Devins and Gold, 2002), In creative enterprises, there is often an emotional engagement between the people and the business, in which its distinctive culture is produced through the style, language, behaviours, and feeling between people. Terms such as "passion", "buzz", "excitement" and "fun" describe the 
emotional life and energy of the enterprise which goes beyond rationality, for people are expressing themselves, their identities and their creative abilities, in the cultural production of the business, and sharing it with the audience. This quality of emotional engagement is often "what works" in creative businesses.

If the enterprise is successful it evolves and grows, becoming larger and more complex in operation and structure, and employing more people. Transitions from informal to formal roles, relationships and structures accompany this process. Significant changes in the founders' and other roles are inevitable as the business develops. Growth can be seen in terms of changing human and social behaviour with productive interpersonal learning and negotiations around the enterprise, rather than simply as an economic process.

This negotiated change in roles is related to entrepreneurial management, in which self-sustaining management capability develops through managers, teams and functional experts taking responsibility for managing the business (Stevenson and Jarillo, 1990), These mutual learning processes, integral to the growth process, depend on managing employee relationships effectively, changing past expectations, sharing practices, and resolving tensions and conflicts in relationships. As people are employed by the business, they become socialised into it and adopt its cultural norms of participation, behaviour and language. This is a learning process of cultural integration and identification by individuals as employees in the business.

The following extract from the Blue Fish case illustrates the selective engagement by the enterprise in networks of external relationships. These are important in accessing social capital, opportunities and resources (Aldrich and Zimmer, 1986; Grégoire et al., 2001), This selectivity in influencing certain groups and developing the social network and perceptions around the business is an integral aspect of entrepreneurial learning:

We get nearly all our leads from referrals and networking. We recognised early on that there are a few people who become key recommenders, we concentrate on young brand managers and make them feel special as clients.

We know we can only work with certain types of clients, ones who actually want to listen. I've always believed in really strong supplier-client partnering, between us we can create something that's fantastic. It doesn't feel right unless they're involved, it needs to be a two-way street.

This suggests that the customer is engaged as an active participant, not as a passive consumer, and that more than economic value is being generated in the interchange; just as the producer is giving something of themselves, so the customer is identifying themselves with the enterprise. Relationships and "rapport" with some customers and suppliers are more productive than with others. The skills of listening, negotiating and storytelling are essential in maintaining effective relationships. The cultural identity of the enterprise is being formed and enacted through the interactions with these external groups. The enterprise depends on its identity, practices and the credibility of its story being accepted and understood within its chosen networks.

\section{Conclusions and application}

There is scope for wider application of the model in theoretical, educational and practical ways beyond the context of the case studies and the creative media industry.
Entrepreneurial learning

331 
JSBED

12,3

332
It can be used to interpret other cases, since what has been observed within these cases is likely to be, to some extent, typical of such processes in entrepreneurial ventures more generally. It is legitimate to generalise at the level of process and theory, in making sense of "how things happen" by interpreting a limited base of case studies (Yin, 1994), This is not to argue for empirical generalisation, but rather to propose that entrepreneurial learning is fundamental within human social development, and that the positions developed in this model may be helpful and applicable in understanding this.

The model does not make claims or assertions about people's cognitive processes. There is, therefore, no basis for comparison with theories which propose rational or economic understanding of entrepreneurial behaviour rooted in cognitive theory (for example, Minniti and Bygrave: 2001; Mitchell et al., 2002; Shepherd and Krueger: 2002), Although cognitivism is pervasive and influential in the literature, as Gergen (1999) observes, there is a strong case to be made against simply accepting this and it is equally valid to propose a social constructionist alternative.

The model instead builds on Wenger's (1998) social theory of learning by adapting it to the activity of entrepreneurial learning, in which some of Wenger's themes become more significant than others, by emphasising the creation, recognition and development of opportunities. The model also draws on social constructionist, narrative and antecedent theories such as constructivism and pragmatism, including Mead (1934), Dewey (1938), Vygotsky (1962), Polkinghorne (1988), Shotter (1993), and Gergen (1999), Until now, no theory of entrepreneurial learning based on social constructionist thinking has been advanced. Therefore, and with reference to the caveats above, this model is proposed as an original and distinctive concept which advances understanding of entrepreneurial learning, both in the context of the creative media industry, and beyond it, using the conceptual tools of narrative and social construction.

It is proposed that there are at least two practical applications for the model. One is educational, the other for business practitioners. Educationally, there is a need for an holistic model of entrepreneurial learning which students can use to make sense of their own learning, practice and development, and the model can be used to assist this. This can support the progression from "teaching about" and towards "learning for entrepreneurship" which is increasingly adopted in entrepreneurship education (Menzies, 2003), This encourages a conceptual yet practical approach to learning to participate in entrepreneurial working, based on personal development, on social and group behaviour, and on opportunity recognition within contextual boundaries. There is scope to develop the model for educational use, in entrepreneurship education and beyond, in new venture creation, in business incubation, and in small firm growth programmes.

The model may also be of value to practitioners because it proposes that personal and social emergence and the corresponding transition in identity is a fundamental aspect of the entrepreneurial experience, not simply skills and knowledge which are assimilated cognitively. For example the themes can be used to generate learning maps to reflect on personal learning. So it may be helpful for emerging entrepreneurs to use the model as a structure to think through such questions as their personal and social identity, how they negotiate their enterprise, and how they use contextual learning to 
recognise opportunities and to develop their own repertoire of "practical theory" from intuitive experience.

\section{References}

Aldrich, H. and Zimmer, C. (1986), "Entrepreneurship through social networks", in Sexton, D.S. and Smilor, R.W. (Eds), The Art and Science of Entrepreneurship, Ballinger, Cambridge, MA, pp. 3-23.

Bandura, A. (1986), Social Foundations of Thought and Action: A Social Cognitive Theory, Prentice-Hall, Englewood Cliffs, NJ.

Binks, M. and Vale, P. (1990), Entrepreneurship and Economic Change, McGraw-Hilll, Maidenhead.

Cope, J. and Watts, G. (2000), "Learning by doing: an exploration of critical incidents and reflection in entrepreneurial learning", International Journal of Entrepreneurial Behaviour and Research, Vol. 6 No. 3.

Davidsson, P., Low, M. and Wright, M. (2001), "Editor's introduction: Low and MacMillan ten years on: achievements and future directions for entrepreneurship research", Entrepreneurship Theory and Practice, Vol. 25 No. 4, pp. 5-15.

Deakins, D. (2000), Entrepreneurship and Small Firms, McGraw-Hill, London.

Deakins, D. and Freel, M. (1998), "Entrepreneurial learning and the growth process in SMEs", The Learning Organization, Vol. 5 No. 3, pp. 144-55.

Devins, D. and Gold, J. (2002), "Social constructionism: a theoretical framework to underpin support for the development of managers in SMEs?", Journal of Small Business and Enterprise Development, Vol. 9 No. 2, pp. 111-9.

Dewey, J. (1991), "Logic: the theory of enquiry", in Boydston, J.A. (Ed.), The Collected Works of John Dewey, Southern Illinois University Press, Carbondale, IL.

Festinger, L. (1957), A Theory of Cognitive Dissonance, Stanford University Press, Stanford, CA.

Gagné, R. (1977), The Conditions of Learning, Holt Rinehart and Winston, New York, NY.

Gergen, K. (1999), An Invitation to Social Construction, Sage, Newbury Park, CA.

Gibb, A. (1993), “The enterprise culture and education”, Entrepreneurship Theory and Practice, Vol. 11 No. 3, pp. 11-34.

Gibb, A. (1996), "Entrepreneurship and small business management: can we afford to neglect them in the twenty-first century business school?", British Journal of Management, Vol. 7 No. 4, pp. 309-21.

Gibb Dyer, W. Jr (1994), “Toward a theory of entrepreneurial careers”, Entrepreneurship Theory and Practice, Vol. 19 No. 2, pp. 7-21.

Gorman, G., Hanlon, D. and King, W. (1997), "Some research perspectives on entrepreneurship education, enterprise education and education for small business management: a ten-year literature review", International Small Business Journal, Vol. 15 No. 3, pp. 56-77.

Grégoire, D., Déry, R. and Béchard, J.-P. (2001), "Evolving conversations: a look at the convergence in entrepreneurship research", paper presented at the Babson/Kaufman Entrepreneurship Research Conference, Wellesley, MA.

Harré, R. (1989), Language Games and Texts of Identity, Sage, London.

Hjorth, D. and Steyaert, C. (Eds) (2004), Narrative and Discursive Approaches in Entrepreneurship, Edward Elgar, Cheltenham.

Jack, S. and Anderson, A. (1999), "Entrepreneurship education within the enterprise culture", International Journal of Entrepreneurial Behaviour and Research, Vol. 5 No. 3, pp. 110-25.

Entrepreneurial learning

333 
JSBED

12,3

334
Kelly, G. (1955), The Psychology of Personal Constructs, Norton, New York, NY.

Kirzner, I. (1973), Competition and Entrepreneurship, University of Chicago Press, Chicago, IL.

Kolb, D. (1984), Experiential Learning: Experience as the Source of Learning and Development, Prentice-Hall, Englewood Cliffs, NJ.

Leadbeater, C. and Oakley, K. (1999), The Independents: Britain's New Cultural Entrepreneurs, Demos, London.

Mead, G. (1934), Mind, Self and Society, University of Chicago Press, Chicago, IL.

Menzies, T. (2003), "21st century pragmatism: universities and entrepreneurship education and development", paper presented at the 48th International Council for Small Business Conference, Belfast.

Minniti, M. and Bygrave, W. (2001), “A dynamic model of entrepreneurial learning", Entrepreneurship Theory and Practice, Vol. 25 No. 3, pp. 5-16.

Mitchell, R., Busenitz, L., Lant, T., McDougall, P. and Morse, E. (2002), "Towards a theory of entrepreneurial cognition", Entrepreneurship Theory and Practice, Vol. 27 No. 2, pp. 93-104.

Mitton, D. (1997), "Entrepreneurship: one more time - non-cognitive characteristics that make the cognitive click", Frontiers of entrepreneurship research, Vol. 4, pp. 189-203.

Mumford, A. (1995), Effective Learning, Institute of Personnel and Development, London.

Parker, S. (2004), "Learning about the unknown: how fast do entrepreneurs adjust their beliefs?", paper presented at 49th ICSB World Conference, Johannesburg.

Polkinghorne, D. (1988), Narrative Knowing and the Human Sciences, SUNY Press, New York, NY.

Potter, J. and Weatherall, M. (1987), Discourse and Social Psychology, Sage, London.

Rae, D. (2003), "Entrepreneurial identity and capability: the role of learning", $\mathrm{PhD}$ thesis, The Nottingham Trent University, Nottingham.

Rae, D. (2004), "Practical theories from entrepreneurs' stories: discursive approaches to entrepreneurial learning", Journal of Small Business and Enterprise Development, Vol. 11 No. 2, pp. 195-202.

Rae, D. and Carswell, M. (2001), "Towards a conceptual understanding of entrepreneurial learning", Small Business and Enterprise Development, Vol. 8 No. 2, pp. 150-8.

Raffo, C., O'Connor, J., Lovatt, A. and Banks, M. (2000), “Attitudes to formal business training amongst entrepreneurs in the cultural industries: situated business learning through 'doing with others"', Journal of Education and Work, Vol. 13 No. 2, pp. 215-30.

Schumpeter, J. (1934), The Theory of Economic Development, Harvard University Press, Boston, MA.

Schwandt, T. (1998), "Constructivist, interpretivist approaches to human inquiry”, in Denzin, N. and Lincoln, Y. (Eds), The Landscape of Qualitative Research, Sage, Thousand Oaks, CA.

Shane, S. and Venkataraman, S. (2000), "The promise of entrepreneurship as a field of research", Academy of Management Review, Vol. 25 No. 1, pp. 217-26.

Shepherd, D. and Krueger, N. (2002), “An intentions-based model of entrepreneurial teams' social cognition”, Entrepreneurship Theory and Practice, Vol. 27 No. 2, p. 167.

Shotter, J. (1993), Conversational Realities: Constructing Life Through Language, Sage, London.

Spinosa, C., Flores, F. and Dreyfus, H. (1997), Entrepreneurship, Democratic Action and the Cultivation of Solidarity, MIT Press, Cambridge, MA.

Stevenson, H. and Jarillo, C. (1990), "A paradigm of entrepreneurship: entrepreneurial management”, Strategic Management Journal, Vol. 11, Summer, pp. 17-27. 
Vygotsky, L. (1962), Thought and Language, MIT Press, Cambridge, MA.

Weick, K. (1995), Sensemaking in Organizations, Sage, Thousand Oaks, CA.

Wenger, E. (1998), Communities of Practice: Learning, Meaning and Identity, Cambridge University Press, Cambridge.

Yin, R.K. (1994), Case Study Research: Design and Methods, Sage, Thousand Oaks, CA.

\section{Further reading}

Young, J. and Sexton, D. (1997), "Entrepreneurial learning: a conceptual framework", Journal of Enterprising Culture, Vol. 5 No. 3, pp. 223-48. 